\title{
Insights into Bioindicator Redundancy for Monitoring Water Quality based on Functional Units of Periphytic Protozoan Communities in Marine Ecosystems
}

Syed Shabi UI Hassan Kazmi

Ocean University of China

Uroosa Uroosa

Ocean University of China

Alan Warren

Natural History Museum

Guangjian Xu

Qingdao University of Science and Technology

Henglong Xu ( $\sim$ henglongxu@126.com )

Ocean University of China https://orcid.org/0000-0003-1954-6647

\section{Research Article}

Keywords: Marine environment, periphytic protozoa, response units, redundancy level, water quality

Posted Date: June 1st, 2021

DOI: https://doi.org/10.21203/rs.3.rs-481939/v1

License: (c) (i) This work is licensed under a Creative Commons Attribution 4.0 International License. Read Full License 


\section{Abstract}

Although periphytic protozoan communities have long been used for the bioassessment of water quality, their utility is hampered by functional redundancy leading to high "signal to noise" ratios. In this study, a 1-year baseline survey of periphytic protozoan communities was carried out in coastal waters of Yellow sea, northern China, in order to determine redundancy levels in conditions of differing water quality. Samples were collected at four sampling sites along a pollution gradient. Environmental variables such as salinity, chemical oxygen demand (COD), and concentrations of dissolved oxygen (DO), soluble reactive phosphates (SRP), ammonium nitrogen $\left(\mathrm{NH}_{4}-\mathrm{N}\right)$ and nitrate nitrogen $\left(\mathrm{NO}_{3}-\mathrm{N}\right)$ were measured to compare with biotic factors. A total of 53 functional units (FUs) were identified from 144 observed protozoan species based on four biological traits, i.e., feeding type, body size, movement type and source of food supply. For reducing the "signal to noise" ratios of species-abundance/biomass data, the peeling procedure was used to identify the bioindicator redundancy levels based on these FUs. Three consecutive subsets of response units (RU1-RU3) with correlation coefficients $>0.75$ of the full FU dataset were identified, comprising 12, 21 and 9 FUs, respectively. Algivores and bacterivores were dominant in RU1 and RU2 among the polluted sites, whereas raptors were dominant in RU3 at the unpolluted site. In terms of relative abundance, RU1 was the primary contributor to the protozoan communities during the 1-year cycle and its relative abundance increased with increasing pollution, whereas RU2 and RU3, with complementary temporal distributions, generally decreased with increasing pollution. Ordinations based on boot-strapped average analyses revealed a significant variation in functional pattern of all three RUs among the four sampling sites. Biological-environmental match analysis demonstrated that the variability was driven by the increasing concentrations of nutrients (e.g., $\mathrm{NH}_{4}-\mathrm{N}, \mathrm{NO}_{3}-\mathrm{N}$ and $\mathrm{PO}_{4}-\mathrm{P}$ ) and decreasing concentrations of DO $(P<0.05)$. Based on these findings, it is suggested that there were high levels of functional redundancy among periphytic protozoan communities used as bioindicators of marine water quality.

\section{Introduction}

Traditionally, community responses to environmental change are investigated using full species datasets (Jiang et al., 2007, 2014; Xu et al., 2014a, b; Xu et al., 2017). When using such datasets, however, the community-based bioassessment is generally subject to a high "signal to noise" ratio (Clarke, 1993; Clarke and Warwick, 1998; Xu et al., $2014 a, b, 2015 a, b)$. A number of studies have demonstrated the interchangeability of species that serve equivalent functions within an ecosystem (Gray et al., 1998; Zhong et al., 2014; Zhang and Xu, 2015). This indicates that there is substantial structural and functional redundancy within communities (Menge et al., 1994; Chapin et al., 1995; Frost et al., 1995). Therefore, when using community-based bioassessments, the identification of functional redundancy is considered an important operative tool for reducing the "signal to noise" ratios (Clarke, 1993; Clarke and Warwick, 1998; Gray et al., 1998; Zhong et al., 2014). In full species datasets this can be achieved through multivariate analysis by identifying the response units (RUs), i.e., subsets of species with interchangeable functional roles.

Most periphytic protozoa are primary grazers that play a pivotal role in microbial food webs by controlling the flux of matter and energy from lower to higher trophic levels (Azovsky, 1988; Crawford et al., 1997; Finlay and Esteban, 1998; Kchaou et al., 2009; Fischer et al., 2002; Weitere et al., 2003; Zhong et al., 2017; Kazmi et al., 2020b). Furthermore, they typically have relatively short life cycles and high sensitivity to environmental change (Jiang et al., 2011; Xu et al., 2014a; Kazmi et al., 2021). Consequently, periphytic protozoa have been widely used as bioindicators of water quality in many types of aquatic habitat worldwide (Sime-Ngando et al., 1995; Coppellotti and Matarazzo, 2000; Norf et al., 2009; Kathol et al., 2011; Jiang et al., 2011; Zhang et al., 2012; Payne, 2013; Jiang et al., 2014; Zhong et al., 2014; Xu et al., 2014a; Feng et al., 2015; Xu et al., 2017; Kazmi et al., 2021). Nevertheless, their utility is often limited by high "signal to noise" ratios due to the high functional redundancy in such communities (Menge et al., 1994;

Page 2/18 
Chapin et al., 1995; Frost et al., 1995; Clarke and Warwick, 1998; Coppellotti and Matarazzo, 2000; Xu et al., 2014b) and, hitherto, few studies have addressed this problem (Gray et al., 1998; Xu et al., 2017).

In the present study, the peeling procedure was used to identify the response units (RUs) from a functional-unit dataset of periphytic protozoan communities in coastal waters of the Yellow sea, northern China, during a 1-year cycle. The main aims of the study were: (1) to identify the redundancy levels of response units in the periphytic protozoan communities; (2) to explore spatio-temporal fluctuations in functional patterns of response units in these communities, and; (3) to reveal the spatio-temporal variations in different functional redundancy levels in response to certain environmental parameters.

\section{Materials And Methods}

Study area and dataset collection

The study area was located in coastal waters of the Yellow Sea, northern China (Fig. 1a, b). Four study sites were selected based on a pollution gradient (Fig. 1c): site A, located in a relatively unpolluted area at the Olympic Sailing Center; site B, located in a slightly polluted area near the mouth of Jiaozhou Bay; site C, located in a moderately polluted area due to rivers discharging into Jiaozhou Bay; and site D, located in a heavily polluted area of Jiaozhou Bay mainly due to organic pollutants and nutrients from domestic sewage and industrial effluents entering the bay via several rivers (Fig. 1c).

Periphytic protozoan communities were sampled every month over a 1-year cycle from August 2011 to July 2012, using glass microscope slides $(2.5 \times 7.5 \mathrm{~cm})$ as artificial substrates. The slides were immersed $1 \mathrm{~m}$ below the water surface and left for 14 days to allow colonization by periphytic protozoa. On each sampling occasion two PVC frames, each having 10 slides giving a total of 20 slides for each site, were collected. In total, 960 slides were examined during the course of the study. Upon retrieval, the slides were transferred into Petri dishes containing in situ water and were processed within $2 \mathrm{~h}$ according to the methods described by Xu et al. $(2014 \mathrm{a}, \mathrm{b})$.

Identification and Enumeration

Identification and enumeration of periphytic protozoa were performed under an inverted microscope at magnifications of 10-400X. Published guides such as Song et al. (2009) were used for species identification. The enumeration strategy was according to Xu et al. (2014b).

A WTW Multi 3500i sensor was used to measure the water temperature ( $\mathrm{T}$ ), pH, salinity (Sal) 3 and dissolved oxygen concentration (DO) at each sampling site. Concentrations of ammonium nitrogen $\left(\mathrm{NH}_{4}-\mathrm{N}\right)$, nitrate nitrogen $\left(\mathrm{NO}_{3}-\mathrm{N}\right)$, nitrite nitrogen $\left(\mathrm{NO}_{2}-\mathrm{N}\right)$, and soluble reactive phosphate (SRP) were measured according to the "Standard Protocols for the Examination of Water and Wastewater" (APHA, 1992).

Formulation of response units (RUs)

Functional units of periphytic protozoa were determined based on four biological traits, i.e., feeding type (bacterivores, algivores, non-selectives and predators/raptors), body size (small, medium and large), movement type (vagile, sessile and planktonic), and source of food supply (plankton and periphyton).

Using a peeling procedure based on the routine BVSTEP in the PRIMER v7.1.17 package, the best matching subsets from the matrix of functional-unit abundance data were determined by peeling the former selections (Clarke and Gorley, 2015; Xu et al., 2017). Among these selections, the first subsets with correlation coefficients more than 0.75 to 
the Functional Unit (FU) of the full-species dataset were identified as response units (RUs) of the periphytic protozoan communities (Zhong et al., 2014; Clarke and Gorley, 2015; Xu et al., 2017).

\section{Data analysis}

All multivariate analyses were performed using the PRIMER v7.1.17 (Clarke and Gorley, 2006) and the PERMANOVA + v1.0.7 for PRIMER packages (Anderson et al., 2008). Shade plotting with cluster analysis was used to summarize the co-occurrence and distribution of RUs of the periphytic protozoan communities at each sampling site (Anderson et al., 2008). Bootstrapped average analysis with metric multidimensional scaling (mMDS) ordinations were computed to show the relationships between environmental variables and variations in RUs (Clarke and Gorley, 2015). The submodule BIOENV (biota-environment correlation analysis) was used to explore the potential environmental drivers for variations of the RUs along the pollution gradient, and the significance level of biota-environment correlations was tested using the routine RELATE (Clarke and Gorley, 2006; Xu et al., 2008; Jiang et al., 2011, 2013b; Xu et al., 2014a).

Correlation analyses were performed using statistical program SPSS v16.0 to observe the Pearson relationships between RUs and environmental variables. Data were log-transformed before analyses (Xu et al., 2008; Xu et al., 2014a).

\section{Results}

Physico-chemical/environmental variables

The mean values of physico-chemical factors at the four sampling sites are shown in Table S1. Clear variations were observed in abiotic factors along the pollution gradient from site A to site D. It is noteworthy that site D (in the most heavily polluted area) had the lowest salinity and $\mathrm{pH}$ values whereas $\mathrm{DO}$ and transparency gradually decreased from site $A$ to site $\mathrm{D}$. In contrast, concentrations of $\mathrm{NH}_{4}-\mathrm{N}, \mathrm{SRP}$ and $\mathrm{NO}_{3}-\mathrm{N}$ increased from site $A$ to site $\mathrm{D}$ (Table S1).

Functional redundancy levels and response units

A total of 144 protozoan species were observed, which were assigned to 53 FUs (Table S2). Of these, three sequential subsets of RUs were identified. The first subset comprised 12 FUs and its mMDS ordinations closely matched the patterns of the full FUs (Fig. 2a, b). The second subset with 21 FUs and third subset with nine FUs represented continuous peeling (Fig. 2c and d). The degree to which the patterns of mMDS ordinations of the residual subsets (Fig. 2e) matched that of the full FUs (Fig. 2a) was significantly reduced compared to the other three subsets.

Spatial distribution of response units

The distribution of response units RU1, RU2 and RU3 among the four study sites are summarized in (Fig. 3). Stochastic patterns of distribution are shown by these RUs along the pollution gradient from site A to site D. In RU1, raptors with inside food supply (RIS4s) and bacterivores with outside food supply (BOS5s) dominated at site $A$ (Fig. 3a). In RU2, by contrast, algivores with inside food supply (AIS4p\&v) and bacterivores with outside food supply (BOS5s) were primary contributors at sites B and C (Fig. 3b). It is noteworthy, however, that in RU3 an interchangeable patterns were shown by protozoan communities, with the most heavily polluted site (site $\mathrm{D}$ ) mostly dominated by bacterivores with outside food supply (BOS2s) and non-selective with outside food supply (NOS4v), respectively (Fig. 3c). 
The spatial distribution of 53 FUs and their co-occurrence with RUs among the four sampling sites are summarized in Fig. 4. Based on the index of association matrix from standardized FU-abundance data, clustering analysis divided the three subsets of RUs into three groups (I-III) (Fig. 4). Groups I and II showed a conspicuous decreasing trend particularly in groups Ila and IIb along the pollution gradient from site A, the most unpolluted site, to site $D$, the most heavily polluted site, whereas group III had the opposite distribution. The residual subunits (RES) had uneven occurrence patterns among the four sites (Fig. 4).

Spatio-temporal variations in response unit patterns

The response units of protozoan FUs showed significant temporal variations among the four study sites (Fig. 5). In terms of relative abundance, site A was dominated by RU1 from July to August whereas RU2 dominated in January and June (Fig. 5a). At sites B, C and D, the relative abundance of RU1 and RU2 fluctuated from January to December while, RU3 and RES had low abundance as compared to RU1 and RU2 (Fig. 5b and c). However, high abundance of RU1 was recorded throughout the 12-month period of study and was dominant at site D (Fig. 5d).

The spatial variations of response units in terms of their relative abundance are shown in Fig. 6 . Significant spatial variations are represented by the response units: RU1 was dominant at all four sites, RU2 had maximum relative abundance at site A, and RU3 and RES had low relative abundance at all sites (Fig. 6).

Linkage between environmental variables and response units

Bootstrapped average analysis based on metric multidimensional scaling mMDS ordinations on both biotic and biotic matrices showed similar patterns between the environmental variables and response units (Fig. 7). RELATE analysis revealed statistically significant relationships between RU1, RU2, RU3 and environmental variables $(\rho=$ 0.435, $\rho=0.454, \rho=0.247 ; P<0.05)$.

Multivariate biota-environment (BIOENV) analysis showed the top 10 matches of environmental variables with the patterns of RUs. These included nutrients $\left(\mathrm{NO}_{3}-\mathrm{N}, \mathrm{NH}_{4}-\mathrm{N}\right.$ and $\left.\mathrm{PO}_{4}-\mathrm{P}\right)$ in combination with $\mathrm{pH}$ and $\mathrm{DO}$ (Table 1).

Furthermore, Pearson correlation between environmental variables and response units of FUs are summarized in Table 2. For example RU1, RU2 and RU3 were significantly positively correlated with salinity and pH but negatively correlated with nutrients, whereas RES was positively correlated with nutrients and COD (Table. 2).

Table 1 Summary of results from biota-environment (BIOENV) analysis showing the 10 best matches of environmental variables with spatial variations in the abundance of RUs (RU1-RU3) at four sampling sites in coastal waters of the Yellow Sea, near Qingdao, northern China during the study period. 


\begin{tabular}{|c|c|c|c|}
\hline Ranks & Environmental variables & $\rho$ value & $P$ value \\
\hline \multicolumn{4}{|l|}{ RU-1 } \\
\hline 1 & $\mathrm{pH}$ & 0.618 & $<0.05$ \\
\hline 2 & $\mathrm{pH}, \mathrm{DO}$ & 0.576 & $<0.05$ \\
\hline 3 & $\mathrm{pH}, \mathrm{DO}, \mathrm{NO}_{3}-\mathrm{N}$ & 0.550 & $<0.05$ \\
\hline 4 & $\mathrm{pH}, \mathrm{NO}_{3}-\mathrm{N}$ & 0.530 & $<0.05$ \\
\hline 5 & $\mathrm{pH}, \mathrm{DO}, \mathrm{PO}_{4}-\mathrm{P}$ & 0.508 & $<0.05$ \\
\hline 6 & $\mathrm{pH}, \mathrm{PO}_{4}-\mathrm{P}$ & 0.508 & $<0.05$ \\
\hline 7 & $\mathrm{pH}, \mathrm{DO}, \mathrm{NO}_{3}-\mathrm{N}, \mathrm{PO}_{4}-\mathrm{P}$ & 0.494 & $<0.05$ \\
\hline 8 & $\mathrm{pH}, \mathrm{DO}, \mathrm{NH}_{4}-\mathrm{N}$ & 0.493 & $<0.05$ \\
\hline 9 & $\mathrm{pH}, \mathrm{DO}, \mathrm{NO}_{3}-\mathrm{N}, \mathrm{NH}_{4}-\mathrm{N}$ & 0.477 & $<0.05$ \\
\hline 10 & $\mathrm{pH}, \mathrm{NH}_{4}-\mathrm{N}$ & 0.470 & $<0.05$ \\
\hline \multicolumn{4}{|l|}{ RU-2 } \\
\hline 1 & $\mathrm{pH}, \mathrm{DO}$ & 0.549 & $<0.05$ \\
\hline 2 & $\mathrm{pH}$ & 0.544 & $<0.05$ \\
\hline 3 & $\mathrm{pH}, \mathrm{DO}, \mathrm{NH}_{4}-\mathrm{N}$ & 0.484 & $<0.05$ \\
\hline 4 & $\mathrm{~S}, \mathrm{pH}, \mathrm{DO}$ & 0.478 & $<0.05$ \\
\hline 5 & $\mathrm{pH}, \mathrm{DO}, \mathrm{NO}_{2}-\mathrm{N}$ & 0.478 & $<0.05$ \\
\hline 6 & $\mathrm{pH}, \mathrm{DO}, \mathrm{NO}_{3}-\mathrm{N}$ & 0.466 & $<0.05$ \\
\hline 7 & $\mathrm{pH}, \mathrm{DO}, \mathrm{PO}_{4}-\mathrm{P}$ & 0.454 & $<0.05$ \\
\hline 8 & $\mathrm{pH}, \mathrm{NO}_{2}-\mathrm{N}$ & 0.451 & $<0.05$ \\
\hline 9 & $\mathrm{~S}, \mathrm{pH}$ & 0.448 & $<0.05$ \\
\hline 10 & $\mathrm{~S}, \mathrm{pH}, \mathrm{DO}, \mathrm{NO}_{3}-\mathrm{N}$ & 0.443 & $<0.05$ \\
\hline \multicolumn{4}{|l|}{ RU-3 } \\
\hline 1 & $\mathrm{pH}, \mathrm{NO}_{2}-\mathrm{N}$ & 0.384 & $<0.05$ \\
\hline 2 & $\mathrm{pH}$ & 0.358 & $<0.05$ \\
\hline 3 & $\mathrm{pH}, \mathrm{DO}, \mathrm{NO}_{2}-\mathrm{N}$ & 0.356 & $<0.05$ \\
\hline 4 & $\mathrm{pH}, \mathrm{DO}$ & 0.330 & $<0.05$ \\
\hline 5 & $\mathrm{pH}, \mathrm{DO}, \mathrm{NO}_{2}-\mathrm{N}, \mathrm{NO}_{3}-\mathrm{N}$ & 0.288 & $<0.05$ \\
\hline 6 & $\mathrm{~S}, \mathrm{pH}, \mathrm{DO}, \mathrm{NO}_{2}-\mathrm{N}$ & 0.286 & $<0.05$ \\
\hline
\end{tabular}




\begin{tabular}{|lllc|}
\hline 7 & $\mathrm{pH}, \mathrm{NO}_{2}-\mathrm{N}, \mathrm{NO}_{3}-\mathrm{N}$ & 0.279 & $<0.05$ \\
\hline 8 & $\mathrm{~S}, \mathrm{pH}, \mathrm{NO}_{2}-\mathrm{N}$ & 0.279 & $<0.05$ \\
\hline 9 & $\mathrm{pH}, \mathrm{DO}, \mathrm{NO}_{3}-\mathrm{N}$ & 0.271 & $<0.05$ \\
\hline 10 & $\mathrm{pH}, \mathrm{DO}, \mathrm{NO}_{2}-\mathrm{N}, \mathrm{PO}_{4}-\mathrm{P}$ & 0.262 & $<0.05$ \\
\hline $\begin{array}{l}\rho \text { value, Spearman correlation coefficient; } P \text { value, statistical significance level. S, salinity; DO, dissolve oxygen; } \\
\mathrm{NH}_{4}-\mathrm{N} \text {, ammonium nitrogen; } \mathrm{NO}_{3}-\mathrm{N} \text {, nitrate nitrogen; } \mathrm{NO}_{2}-\mathrm{N} \text {, nitrite nitrogen; } \mathrm{PO}_{4}-\mathrm{P} \text {, Orthophosphate. }\end{array}$ \\
\hline
\end{tabular}

\section{Table 2}

Pearson correlations between average values of RU-abundance and average of environmental variables at four study sites in coastal waters of the Yellow Sea, near Qingdao, northern China during the study period.

\begin{tabular}{|c|c|c|c|c|c|c|c|c|c|c|c|}
\hline $\mathrm{RU}$ & $\mathrm{T}$ & $S$ & $\mathrm{pH}$ & Do & Tra & $\mathrm{NO}_{2} \mathrm{~N}$ & $\mathrm{NO}_{3} \mathrm{~N}$ & $\mathrm{NH}_{4} \mathrm{~N}$ & $\mathrm{PO}_{4} \mathrm{P}$ & $\mathrm{SiO}_{3} \mathrm{Si}$ & COD \\
\hline RU1 & -0.604 & $0.907 *$ & $0.696 *$ & -0.047 & -0.222 & -0.363 & -0.676 & -0.394 & -0.802 & -0.620 & -0.237 \\
\hline RU2 & -0.732 & $0.917 *$ & $0.568^{*}$ & -0.252 & -0.427 & -0.247 & -0.486 & -0.172 & -0.645 & -0.423 & -0.199 \\
\hline RU3 & -0.650 & $0.549 *$ & $0.404^{\star}$ & -0.112 & -0.199 & -0.792 & -0.721 & -0.432 & -0.850 & -0.604 & -0.703 \\
\hline RES & -0.124 & -0.075 & -0.468 & -0.572 & -0.569 & $0.821^{*}$ & $0.896 *$ & $0.880 *$ & $0.848 *$ & 0.853 & $0.553^{*}$ \\
\hline
\end{tabular}

\section{Discussion}

Previous studies on community-based bioassessment using periphytic protozoan communities have demonstrated a significant correlation between environmental factors, principally water quality status, and (1) spatial variations in community patterns, and (2) species composition and distribution at full species resolution (Xu et al., 2014b; Xu et al., 2015a, b; Xu and Xu 2016a). In contrast, community-level bioindicators based on small taxonomic or functional species pools are considered more effective indicators of environmental heterogeneity (Jiang et al., 2014; Xu et al., 2014b; Zhong et al., 2014; Xu and Xu, 2017). When using communities of organisms for the assessment of water quality status, several studies have revealed a strong "signal to noise" ratio due to functional redundancy when using full-species datasets (Ellis, 1995; Heino and Soininen, 2007; Van der Linden et al., 2012; Zhang et al., 2012; Heymans et al., 2014; Zhong et al., 2014; Hunter Jr. et al., 2016). Therefore, it could be hypothesized that the response units of periphytic protozoan communities at different functional redundancy levels may respond to changes in water quality status.

Various studies on the macrobenthos have revealed the composition of response units from a wide range of functional group assemblages (Warwick and Clarke, 1993; Clarke and Warwick, 1998). However, comparatively little information is available for the microbenthos in general and protozoan communities in particular. Therefore in this 
study, we have used the matrix of FUs of periphytic protozoan communities, i.e., feeding type, source of food supply, body size and mode of locomotion, and identified the three consecutive subsets of response units (RU1, RU2 and RU3) to demonstrate the levels of functional redundancy present. These three subsets were distributed unevenly among four sampling sites (A-D) along a pollution gradient. In particular within RU1, raptors with inside food supply (RIS4s) and bacterivores (BOS5s) with outside food supply were dominant at site A, which was in the most unpolluted area, whereas within RU2 algivores with inside food supply (AIS4p\&v) and bacterivores (BOS5s) with outside food supply were dominant at sites B and C which were moderately polluted areas. Within RU3, bacterivores with outside food supply (BOS5s) accompanied by non-selectives with outside food source (NOS4v) were dominant at site $D$, which was in the most heavily polluted area, and could be the most redundant bioindicators of water quality status. On a temporal scale, the relative abundances of RU1 and RU2 were high throughout the 12-month period of study as compared to RU3. Similarly, on a spatial scale, RU1 and RU2 had high relative abundancies at all four sampling sites compared to RU3. These findings are consistent with previous studies which reported that the total community pattern is sensitive to environmental change, and this pattern does not simply result from trends in one functional group (Clarke and Warwick, 1998). Furthermore, multivariate analysis demonstrated significant relationships between the RUs and environmental variables, particularly the best-matching of the nutrients $\mathrm{NO}_{3}-\mathrm{N}$, $\mathrm{NH}_{4}-\mathrm{N}$ and $\mathrm{PO}_{4}-\mathrm{P}$ in combination with $\mathrm{pH}$ and DO. Moreover, Pearson correlation analysis revealed significantly positive correlations $(P<0.05)$ between $\mathrm{RUs}$ and both water salinity and $\mathrm{pH}$, but negative correlations with nutrients.

Multivariate analysis is considered a more effective tool than univariate analysis for detecting variations in community structure (Clarke and Ainsworth, 1993), whereas both approaches are pivotal for the analysis of community patterns along pollution gradients in aquatic environments (Jiang et al., 2007; Xu et al., 2011). In addition, the peeling procedure (BVSTEP) and multivariate analysis metric multidimensional scaling (mMDS), are also powerful approaches for revealing mechanisms of community ecology. Thus, extended and rigorous studies with substantial datasets are required to fully exploit the predictive capacity of periphytic protozoan communities for monitoring water quality.

\section{Conclusion}

In conclusion, we recovered three successive subsets of response units from the matrix of FUs that seem to perform interchangeable roles on spatio-temporal scales. The relative abundance of the first two subsets (RU1 and RU2) increased along the pollution gradient whereas the relative abundance of the third subset (RU3) generally decreased with increasing pollution levels. Furthermore, algivores and bacterivores were dominant in RU1and RU2 at polluted sites whereas raptors were dominant in RU3 at the unpolluted site. Environmental variations showed significant relationship with the patterns of RUs, in particular with COD and nutrients such as $N_{3}-N_{,} N_{4}-N_{\text {and }} P_{4}-P$. These findings suggest that RUs of periphytic protozoan communities may be used as a useful bioindicators of marine water quality.

\section{Declarations}

\section{Funding}

This study was supported by "The Natural Science Foundation" of China (project number 31672308) and Excellent doctoral award from "Chinese Scholarship Council" (CSC) (Award no.: 2018SOA023059) under the Ministry of Education of China.

\section{Declaration of Interest}


The authors declare that they have no known competing financial interests or personal relationships that could have appeared to influence the work reported in this paper.

\section{Credit authorship contribution statement}

Syed Shabi Ul Hassan Kazmi: Writing Original Draft, Study Designing, Revision Editing; Uroosa: Proof reading; Alan

Warren: Revision; Guangjian Xu: Proof reading; Henglong Xu: Supervision, Conceptualization, and Revision.

\section{Publication/Participation consent}

All authors have participated and approved the final version of manuscript.

\section{Data availability Statement}

Beside the supplementary material, the data will be available on request.

\section{Ethical Approval}

Not Applicable

\section{References}

1. Anderson MJ, Gorley RN, Clarke KR (2008) PERMANOVA+ for PRIMER Guide to software and Statistical Methods. Plymouth: PRIMER-E Ltd.

2. APHA (1992) Standard Methods for Examination of Water and Waste Water, $18^{\text {th }}$ ed. American Public Health Association, Washington, DC.

3. Azovsky Al (1988) Colonization of sand 'islands' by psammophilous ciliates: the effect of microhabitat size and stage of succession. Oikos $51,48-56$.

4. Chapin FS, Lubchenco J, Reynolds HL (1995) Biodiversity effects on patterns and processes of communities and ecosystems. Cambridge University Press, Cambridge

5. Clarke KR (1993) Non-parametric multivariate analyses of changes in community structure. Aust. J. Ecol. 18, 117-143.

6. Clarke KR, Gorley RN (2006) User manual/tutorial. Plymouth: PRIMER-E Ltd.

7. Clarke KR, Gorley RN (2015) PRIMER v7: User Manual/Tutorial. PRIMER-E Ltd, Plymouth, UK.

8. Clarke KR, Warwick RM (1998) Quantifying structural redundancy in ecological communities. Oecologia 113, 278-289.

9. Coppellotti O, Matarazzo P (2000) Ciliate colonization of artificial substrates in the Lagoon of Venice. J. Mar. Biol. Assoc. UK. 80, 419-427.

10. Crawford DW, Purdie DA, Lockwood APM, Weissman P (1997) Recurrent red-tides in the Southampton water estuary caused by the phototrophic ciliate Mesodinium rubrum. Estuar. Coast. Shelf Sci. 45, 799-812.

11. Ellis D (1995) Taxonomic sufficiency in pollution assessment. Mar. Pollut. Bull. 16, 459.

12. Feng M, Zhang W, Wang W, Zhang G, Xiao T, Xu H (2015) Can tintinnids be used for discriminating water quality status in marine ecosystems? Mar. Pollut. Bull. 101, 549-555.

13. Finlay BJ, Esteban GF (1998) Freshwater protozoa: biodiversity and ecological function. Biol. Conserv. 7, 11631186. 
14. Frost TM, Carpenter SR, Ives AR, Kratz TK (1995) Species compensation and complementary in ecosystem function. In: Jones, C.G., Lawton, J.H. (Eds.), Linking Species and Ecosystems. Chapman \& Hall, New York, pp. 224-239.

15. Gray JS, Aschan M, Carr MR, Clarke KR, Green RH, Pearson TH, Rosengerg R, Warwick RM (1998) Analysis of community attributes of the benthic macrofauna of Frierfjord/Langesundfjoird and in a mesocosm experiment. Mar. Ecol. Prog. Ser. 66, 285-299.

16. Heino J, Soininen J (2007) Are higher taxa adequate surrogates for species-level assemblage patterns and species richness in stream organisms? Biol. Conserv. 137 (1): 78-89.

17. Heymans JJ, Coll M, Libralato S, et al (2014) Global Patterns in Ecological Indicators of Marine Food Webs: A Modelling Approach. PLoS ONE 9 (4): e95845.

18. Hunter Jr M, Westgate M, Barton P, et al (2016) Two roles for ecological surrogacy: Indicator surrogates and management surrogates. Ecol. Indic. 63, 121-125.

19. Jiang J, Wu S, Shen Y (2007) Effects of seasonal succession and water pollution on the protozoan community structure in an eutrophic lake. Chemosphere 66, 523-532.

20. Jiang Y, Xu H, Hu X, Zhu M, Al-Rasheid KAS, Warren A (2011) An approach to analyzing spatial patterns of planktonic ciliate communities for monitoring water quality in Jiaozhou Bay, northern China. Mar. Pollut. Bull. 62, 227-235.

21. Jiang Y, Xu H, Warren A (2014) Insights into discriminating environmental quality status using taxonomic distinctness based on a small species pool of ciliated protozoa in marine ecosystems. Sci. Total Environ. 468469, 663-670.

22. Jiang Y, Yang EJ, Min JO, Kang SH, Lee SH (2013b) Using pelagic ciliated microzooplankton communities as an indicator for monitoring environmental condition under impact of summer sea-ice reduction in western Arctic Ocean. Ecol. Indic. 34, 380-390.

23. Kathol M, Fischer $\mathrm{H}$, Weitere $\mathrm{M}$ (2011) Contribution of biofilm-dwelling consumers to pelagic-benthic coupling in a large river. Freshw. Biol. 56, 1017-1230.

24. Kazmi SSUH, Xuexi T, Xu G, Sikder MNA, Xu H (2020b) Vertical variability in taxonomic breadth of biofilmdwelling ciliates in marine bioassessment surveys. Reg. Stud. Mar. Sci. 38, 101366.

25. Kazmi SSUH, Xuexi T, Xu G, Xu H (2021) An approach to optimizing sampling effort for bioassessment surveys based on periphytic ciliates according to water depths in marine ecosystems. Ecol. Ind. 122, 107222.

26. Kchaou N, Elloumi J, Drira Z, Hamza A, Ayadi H, Bouain A, Aleya L (2009) Distribution of ciliates in relation to environmental factors along the coastline of the Gulf of Gabes, Tunisia. Estuar. Coast. Shelf Sci. 83, 414-424.

27. Menge BA, Berlow EL, Blanchette CA, Navarette SA, Yamada SB (1994) The keystone species concept: variation in interaction strength in a rocky intertidal habitat. Ecol. Monogr. 64, 249-286.

28. Norf H, Arndt H, Weitere M (2009) Responses of biofilm-dwelling ciliate communities to planktonic and benthic resource enrichment. Microb. Ecol. 57, 687-700.

29. Payne RJ (2013) Seven reasons why protists make useful bioindicators. Acta Protozool. 52, 105-113.

30. Sime-Ngando T, Gosselin M, Roy S, Chanut JP (1995) Significance of planktonic ciliated protozoa in the lower St. Lawrence estuary: comparison with bacterial, phytoplankton, and particulate organic carbon. Aquat. Microb. Ecol. 9, 243-258.

31. Song W, Warren A, Xu H (2009) Free-Living Ciliates in the Bohai Sea and Yellow Sea, China. Beijing Science Press. 
32. Van der Linden, P., Patrício, J., Marchini, A., Cid, N., Neto, J.M., Marques, J.C., 2012. A biological trait approach to assess the functional composition of subtidal benthic communities in an estuarine ecosystem. Ecol. Indic. 20, $121-133$.

33. Warwick RM, Clarke KR (1993) Comparing the severity of disturbance: a meta-analysis of marine macrobenthic community data. Mar. Ecol. Prog. Ser. 92, 221-231.

34. Xu G, Wang Z, Yang Z, Xu H (2015b) Congruency analysis of biofilm-dwelling ciliates as a surrogate of eukaryotic microperiphyton for marine bioassessment. Mar. Pollut. Bull. 101, 600-604.

35. Xu G, Xu H (2016a) Can annual cyclicity of protozoan communities reflect water quality status in coastal ecosystems? Ecol. Indic. 67, 730-734.

36. Xu G, Xu H (2017) An approach to analysis of functional redundancy in protozoan communities for bioassessment in marine ecosystems. Ecol. Indic. 77, 41-47.

37. Xu G, Zhang W, Xu H (2015a) Can dispersions be used for discriminating water status in coastal ecosystems? A case study on biofilm-dwelling microbial eukaryotes. Ecol. Indic. 57, 208-214.

38. Xu G, Zhong X, Wang Y, Xu H (2014b) A multivariate approach to the determination of an indicator species pool for community-based bioassessment of marine water quality. Mar. Pollut. Bull. 87, 147-151.

39. Xu G, Zhong X, Warren A, Xu H (2017) A multivariate approach to analyzing functional redundancy of marine periphytic ciliates during the colonization process for bioassessment in coastal ecosystems. Mar. Pollut. Bull. 117, 406-413.

40. Xu H, Jiang Y, Al-Rasheid KAS, Al-Farraj SA, Song W (2011) Application of an indicator based on taxonomic relatedness of ciliated protozoan assemblages for marine environmental assessment. Environ. Sci. Pollut. Res. $18,1213-21$.

41. Xu H, Song W, Warren A, Al-Rasheid KAS, Al-Farraj SA, Gong J, Hu H (2008) Planktonic protist communities in a semi-enclosed mariculture pond: structural variation and correlation with environmental conditions. J. Mar. Biol. Assoc. UK. 88 (7): 1353-1362.

42. Xu H, Zhang W, Jiang Y, Yang EJ (2014a) Use of biofilm-dwelling ciliate communities to determine environmental quality status of coastal water. Sci. Total Environ. 470-471, 511-518.

43. Zhang W, Xu H (2015) Seasonal shift in community pattern of periphytic ciliates and its environmental drivers in coastal waters of the Yellow Sea northern China. J. Mar. Biol. Ass. UK 95, 277-288.

44. Zhang $\mathrm{W}, \mathrm{Xu} \mathrm{H}$, Jiang $\mathrm{Y}$, Zhu M, Al-Rasheid KAS (2012) Influence of enumeration time periods on analyzing colonization features and taxonomic relatedness of periphytic ciliate communities using an artificial substratum for marine bioassessment. Environ. Sci. Pollut. Res. 19, 3619-3627.

45. Zhang W, Xu H, Jiang Y, Zhu M, Al-Rasheid KAS (2012) Colonization dynamics in trophic-functional structure of periphytic protist communities in coastal waters. Mar. Biol. 159, 735-748.

46. Zhong X, Xu G, Wang Y, Xu H (2014) An approach to determination of functional species pool for community research. Ecol. Indic. 46, 78-83.

47. Zhong X, Xu G, Xu H (2017) An approach to analysis of colonization dynamics in community functioning of protozoa for bioassessment of marine pollution. Ecol. Ind. 78, 526-530.

\section{Figures}




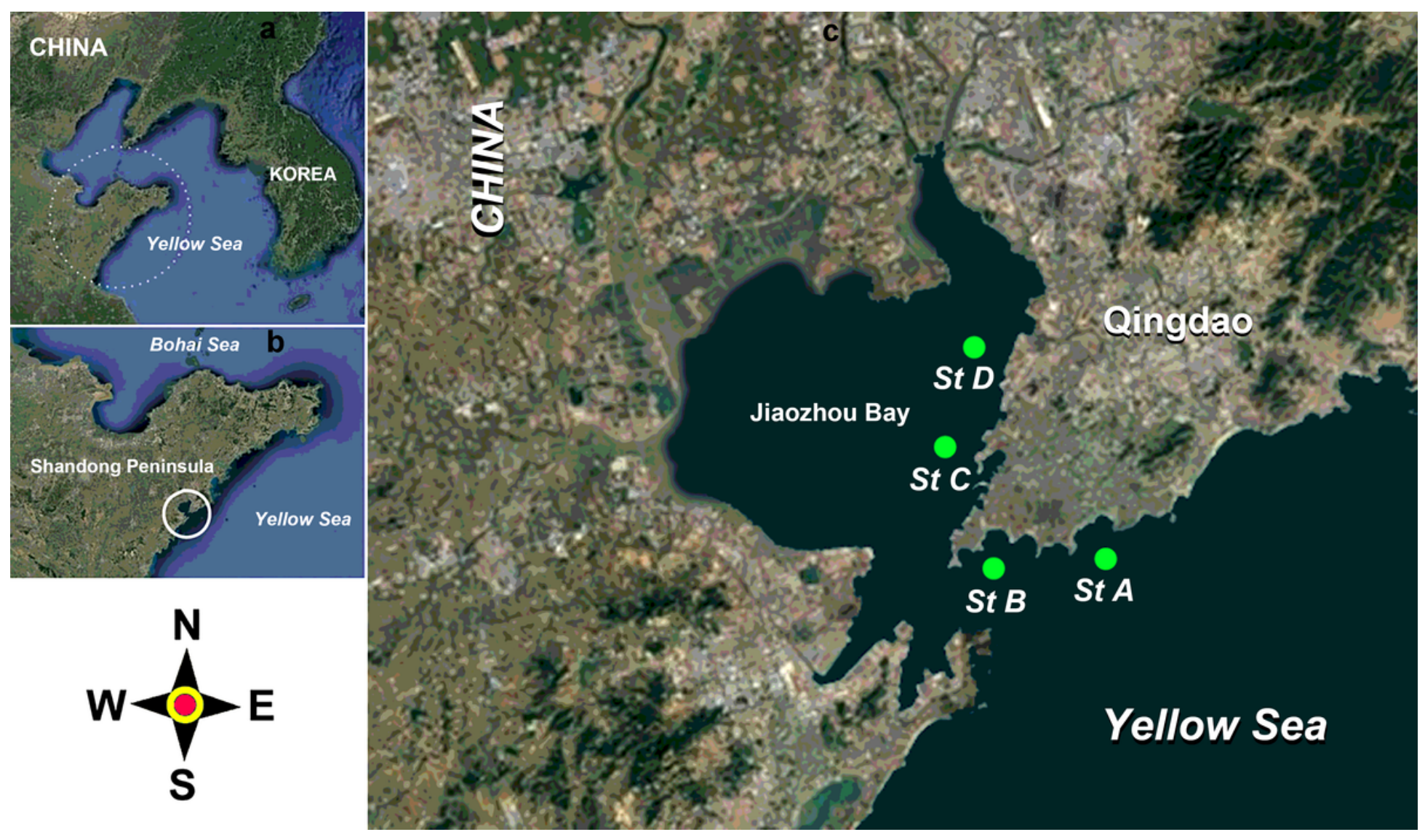

Figure 1

Maps showing the location of the study area $(a, b)$ and sampling sites (c) in coastal waters of the Yellow Sea, near Qingdao, northern China. Site A is in a relatively unpolluted area; site B is in a slightly polluted area near the mouth of Jiaozhou Bay; site $\mathrm{C}$ is in a moderately polluted area due to rivers discharging into Jiaozhou Bay; and site $D$ is in a heavily polluted area of Jiaozhou Bay, mainly due to organic pollutants and nutrients from sewage and industrial effluents that enter the bay via several rivers. Note: The designations employed and the presentation of the material on this map do not imply the expression of any opinion whatsoever on the part of Research Square concerning the legal status of any country, territory, city or area or of its authorities, or concerning the delimitation of its frontiers or boundaries. This map has been provided by the authors. 
a

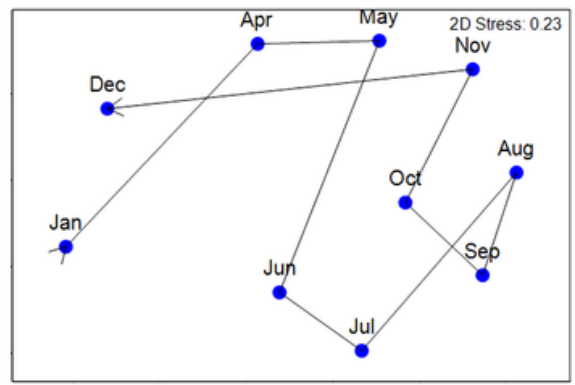

d

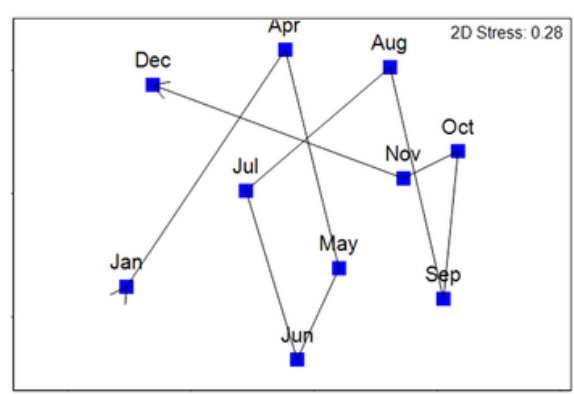

b

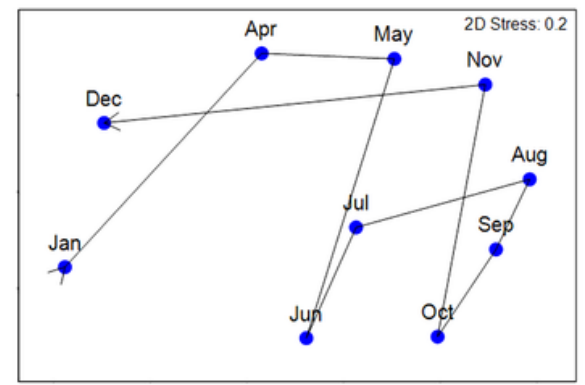

e

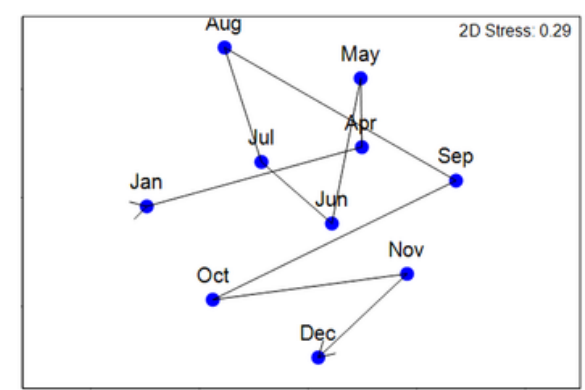

C

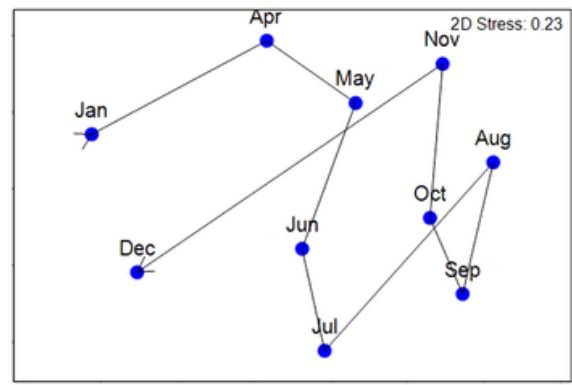

\section{Figure 2}

mMDS ordinations of Response Units (RUs) of functional units of periphytic protozoan communities in coastal waters of the Yellow Sea, showing the remarkable extent to which the overall community pattern (a), a complex matrix of full FUs during a 1-year cycle, is matched by a succession of three small, mutually exclusive subsets, i.e., response units $(b-d)$, generated by the peeling procedure. The degree to which the pattern of the residual subsets (e) matches the full dataset is significantly reduced compared to the other three subsets. 
a

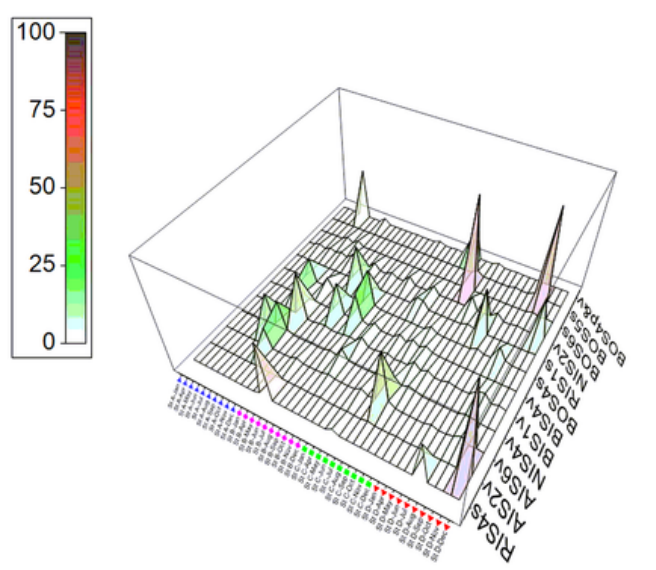

RU1

AtA

- StB

StC
StD

b

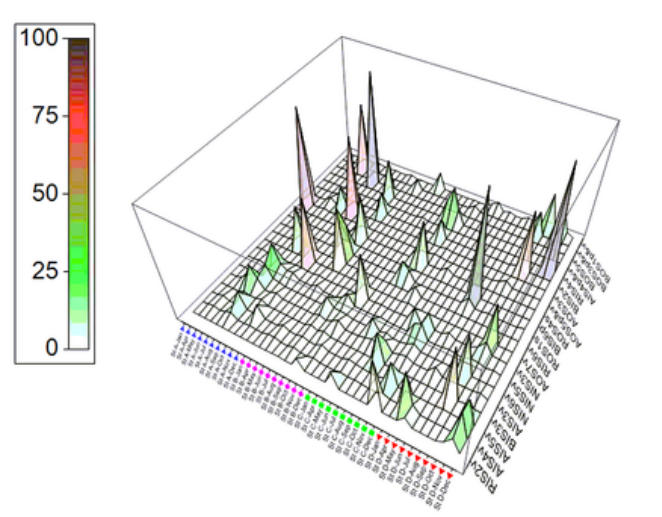

RU2

$\Delta$ StA

- StB

$\checkmark$ StD

C
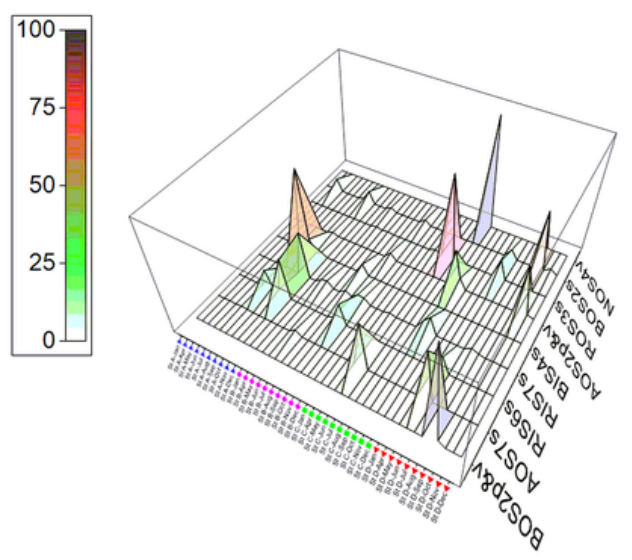

RU3

$\triangle$ StA

$\checkmark$ StB

StC

$\nabla$ StD

\section{Figure 3}

Surface plot of response units (RUs), showing the spatial distribution and composition of the periphytic protozoan response units during a 1-year cycle at four sites $(A-D)$ in coastal waters of the Yellow Sea, northern China. 


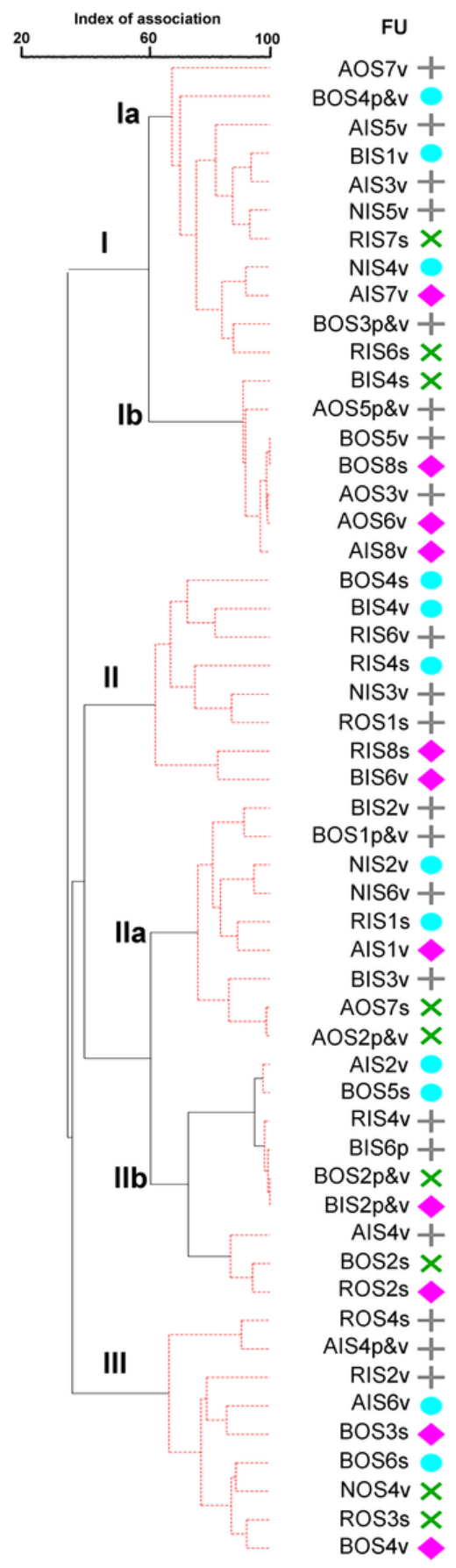

$\begin{array}{llll}\text { St A } & \text { St B } & \text { St C St D }\end{array}$

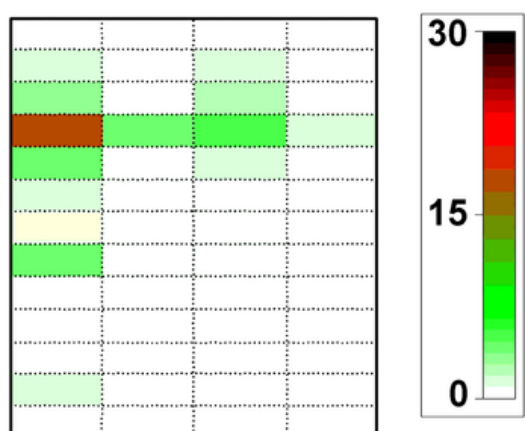

\section{Figure 4}

Shade plot with cluster analysis on index of association, showing the functional unit distribution and co-occurrence of response units of periphytic protozoa among four study sites $(A-D)$ in coastal waters of Yellow sea, northern China. 


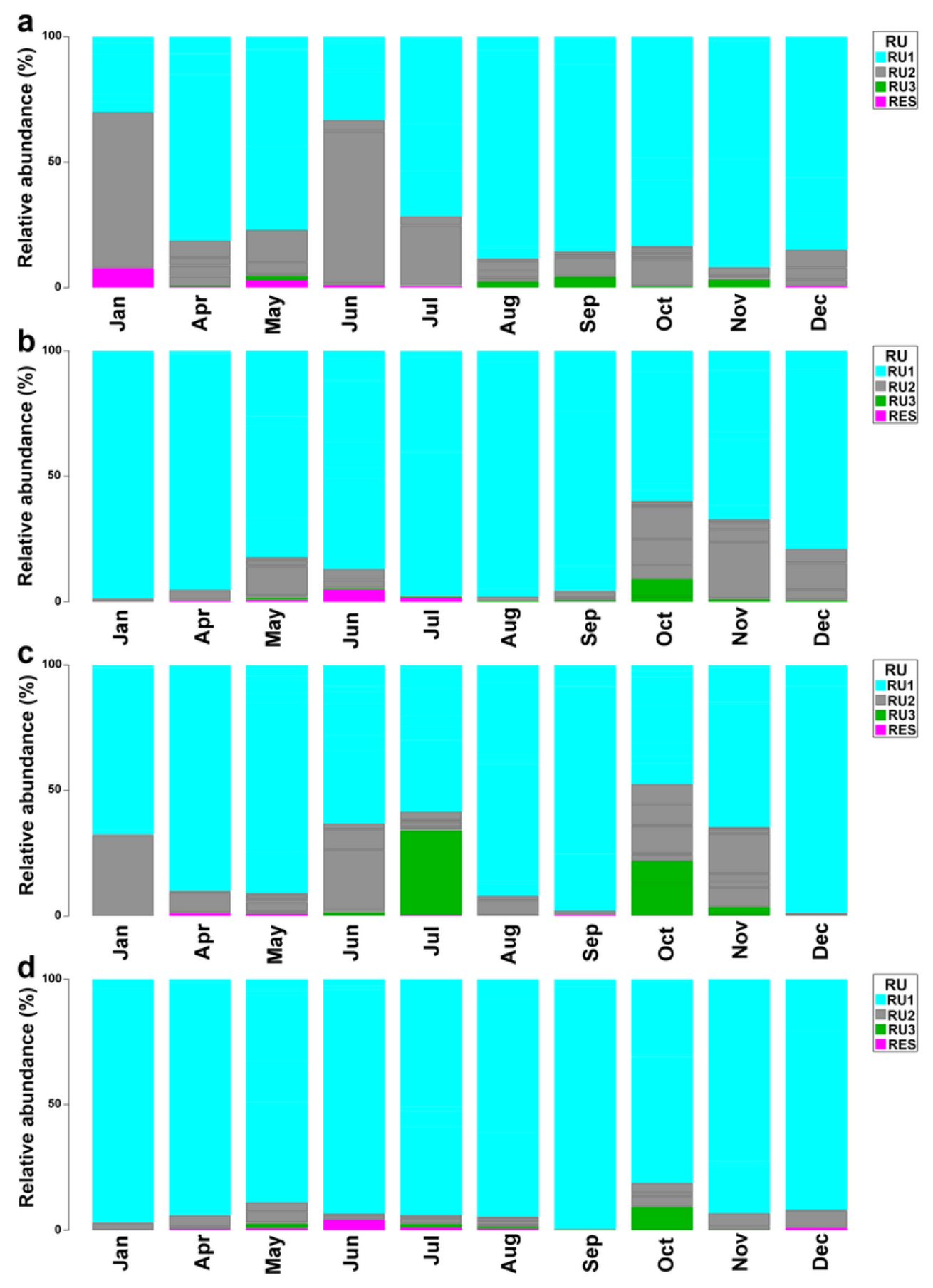

\section{Figure 5}

Temporal variations in relative abundances of RUs at four sampling sites (A-D); a) shows the data for site $A, b)$ shows the data for site $B, C$ ) shows the data for site $C$, and d) shows the data for site D. Abbreviations: RU1, response unit 1; RU2, response unit 2; RU3, response unit 3; RES, residual subunits. 


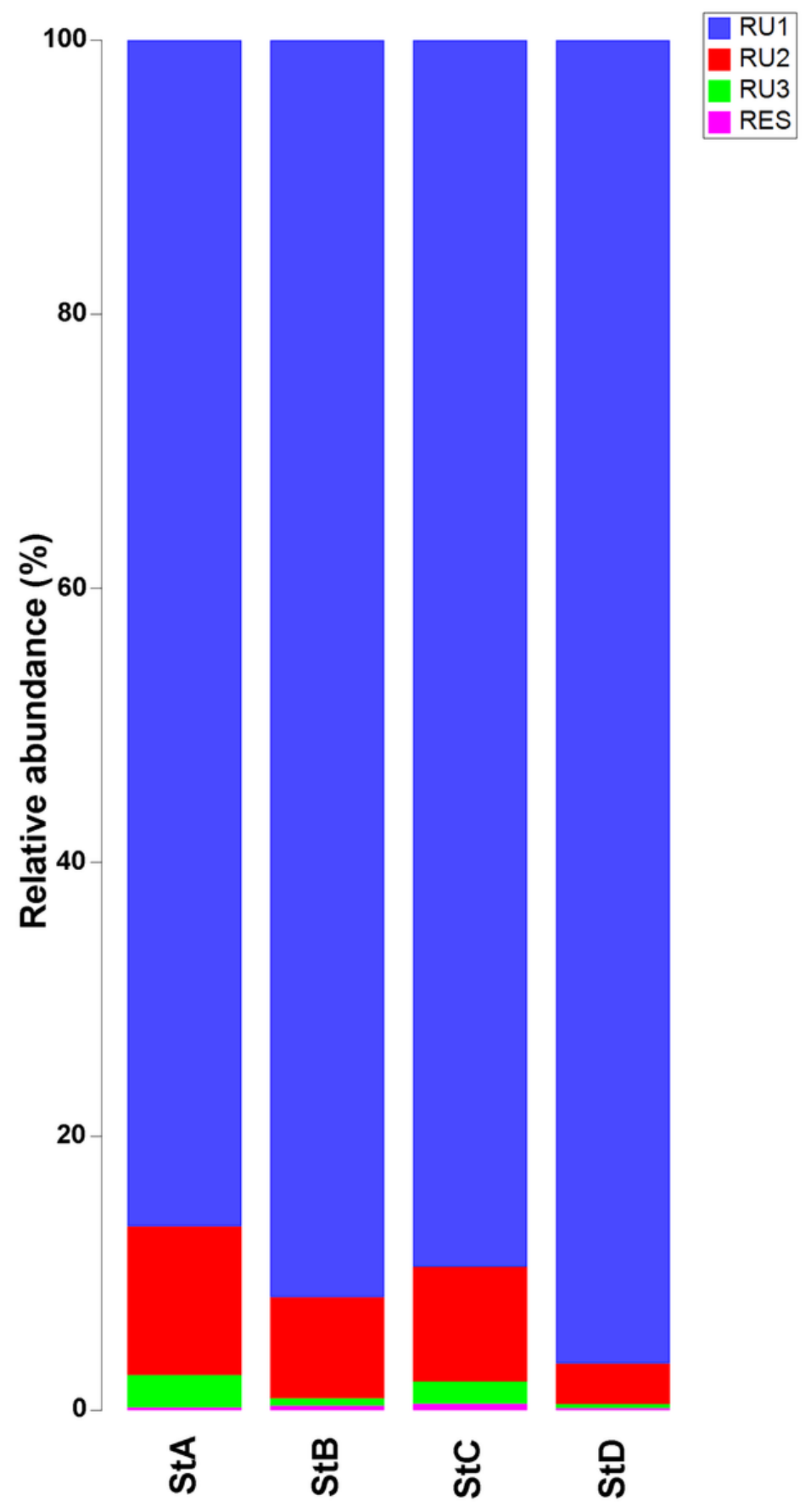

\section{Figure 6}

Spatial variations in average relative abundances of RUs at four sampling sites (StA-StD). Abbreviations: RU1, response unit 1; RU2, response unit 2; RU3, response unit 3; RES, residual subunits. 

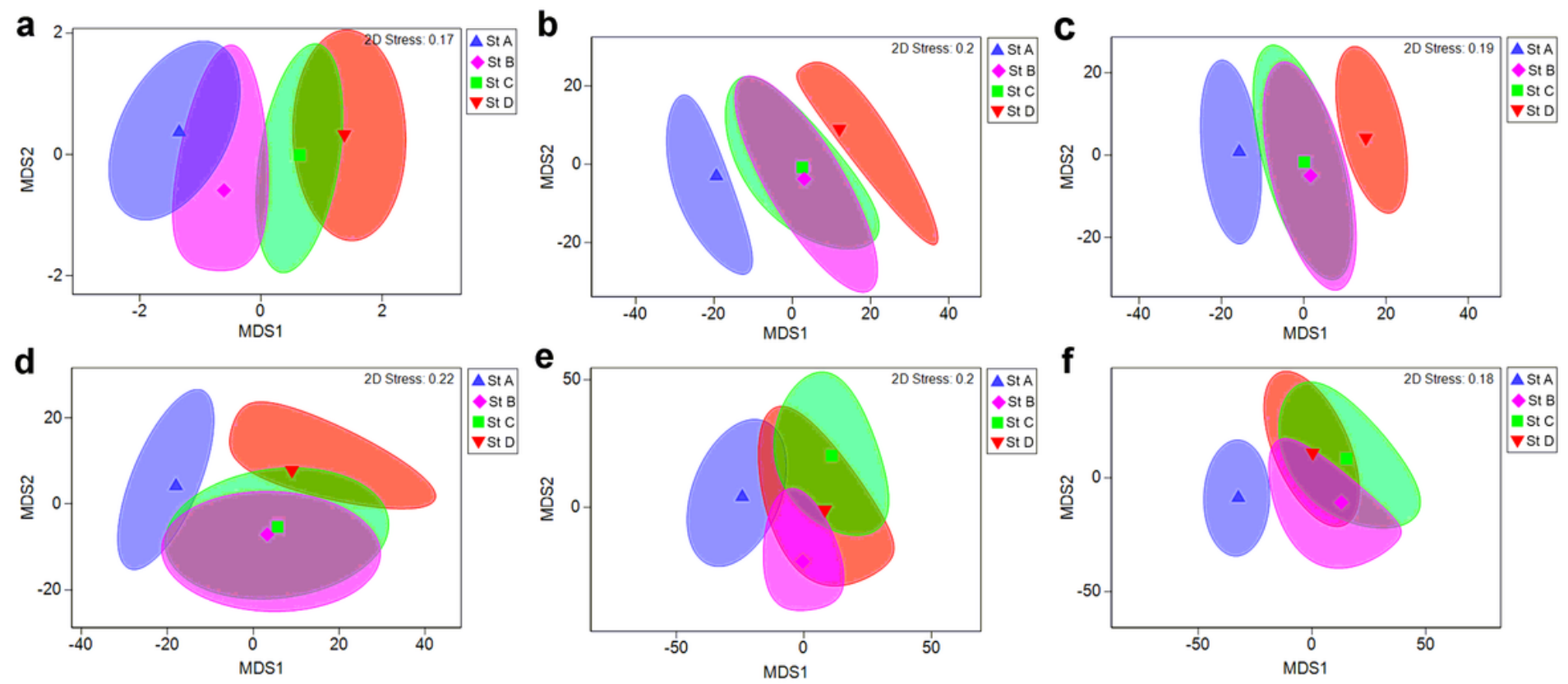

\section{Figure 7}

Bootstrapped average analysis with metric multidimensional mMDS scaling ordinations, showing relationships between environmental conditions (a), and full FUs (b), RU1 (c), RU2 (d), RU3 (e) and RES (f), among the four sampling sites (StA-StD).

\section{Supplementary Files}

This is a list of supplementary files associated with this preprint. Click to download.

- Tables1.doc

- TableS2.docx 